\title{
Diabetes mellitus is a predictive factor for radiation pneumonitis after thoracic radiotherapy in patients with lung cancer
}

This article was published in the following Dove Press journal: Cancer Management and Research

\author{
Moonkyoo Kong' \\ Yu Jin Lim' \\ Youngkyong Kim' \\ Mi Joo Chung ${ }^{2}$ \\ Soonki Min' \\ Dong Oh Shin' \\ Weonkuu Chung ${ }^{2}$ \\ 'Department of Radiation Oncology, \\ Kyung Hee University Medical Center, \\ Kyung Hee University School of \\ Medicine, Seoul, Republic of Korea; \\ ${ }^{2}$ Department of Radiation Oncology, \\ Kyung Hee University Hospital at \\ Gangdong, Kyung Hee University School \\ of Medicine, Seoul, Republic of Korea
}

Correspondence: Weonkuu Chung Department of Radiation Oncology, Kyung Hee University Hospital at Gangdong, Kyung Hee University School of Medicine, 892 Dongnam-ro, Gangdong-gu, Seoul 05278, Republic of Korea

Tel +82 24406071

Fax +82 24407393

Email wkchung@khnmc.or.kr
Purpose: We evaluated the effects of diabetes mellitus (DM) and DM-related serologic factors (HbA1c and fasting glucose) on the development of radiation pneumonitis in patients with lung cancer.

Methods: We retrospectively analyzed the clinical data of 123 patients with lung cancer treated with radiotherapy. Radiation pneumonitis was scored according to the toxicity criteria of the Radiation Therapy Oncology Group. We used binary logistic regression analysis to find significant predictive factors for the development of grade $\geq 3$ radiation pneumonitis.

Results: On univariable analysis, V20, mean lung dose, DM, HbA1c, and fasting glucose level were significantly associated with the development of grade $\geq 3$ radiation pneumonitis. On multivariable analysis, V20, mean lung dose, DM, HbA1c, and fasting glucose level remained significant predictive factors for grade $\geq 3$ radiation pneumonitis. The incidence of grade $\geq 3$ radiation pneumonitis was $44.4 \%$ in patients with DM and $20.7 \%$ in patients without DM. The incidence of grade $\geq 3$ radiation pneumonitis was $12.7 \%$ for $\mathrm{HbA} 1 \mathrm{c}$ level $\leq 6.15 \%$ and $41.5 \%$ for $\mathrm{HbA} 1 \mathrm{c}$ level $>6.15 \%$. The incidence of grade $\geq 3$ radiation pneumonitis was $17.2 \%$ for fasting glucose level $\leq 121 \mathrm{mg} / \mathrm{dL}$ and $35.5 \%$ for fasting glucose level $>121 \mathrm{mg} / \mathrm{dL}$.

Conclusion: $\mathrm{DM}, \mathrm{HbA1c}$, and fasting glucose level are significant predictive factors for the development of grade $\geq 3$ radiation pneumonitis in patients with lung cancer. Patients with $\mathrm{DM}$, patients who have HbA1c $>6.15 \%$, and patients who have fasting glucose $>121 \mathrm{mg} / \mathrm{dL}$ should be treated with greater caution.

Keywords: lung cancer, radiotherapy, radiation pneumonitis, diabetes mellitus

\section{Introduction}

Radiotherapy (RT) is a fundamental treatment modality in the management of lung cancer. Definitive RT with concurrent chemotherapy is the standard treatment for patients with unresectable locally advanced lung cancer. In addition, radiosurgery has been recently used in patients with resectable early-stage lung cancer. ${ }^{1}$ Radiation pneumonitis is one of the most common toxicities following thoracic RT, and the incidence of symptomatic radiation pneumonitis is estimated to be in the range of 15 $45 \%$. $^{2-5}$ Because radiation pneumonitis can significantly compromise the quality of life and can reduce the overall survival of patients with lung cancer who received RT, ${ }^{6}$ several studies have reported predictive factors for radiation pneumonitis. ${ }^{3,7-10}$

Several investigators have reported diabetes mellitus (DM) as a significant predictive factor for radiation toxicities in several cancers. In prostate cancer patients, greater 
incidence of radiation-induced gastrointestinal and genitourinary toxicities was seen in patients with DM. ${ }^{11-15}$ In breast and colorectal cancer, studies have also reported that radiation toxicities were more common in patients with DM than patients without DM. ${ }^{16,17}$ However, studies investigating the correlations between DM and radiation toxicities in lung cancer patients are rare. One preliminary study, published only in abstract form, reported that DM can be associated with the development of radiation pneumonitis in lung cancer patients. ${ }^{18}$ In People's Republic of China, Zhou et al retrospectively analyzed the clinical data of 332 lung cancer patients and reported that the incidence of radiation pneumonitis was significantly higher in the DM group than in non-DM group. ${ }^{19}$ However, Zhou et al's paper is written in Chinese, so we were unable to analyze the full text. Yet, it remains unclear whether DM is associated with the development of radiation pneumonitis in patients with lung cancer.

In this study, we evaluated the effects of DM and DMrelated serologic factors (HbAlc and fasting glucose) on the development of radiation pneumonitis in patients with lung cancer.

\section{Materials and methods}

Inclusion criteria were histologically proven primary lung cancer, receipt of RT with or without chemotherapy, receipt of a total RT dose $\geq 50 \mathrm{~Gy}$, Eastern Cooperative Oncology Group (ECOG) performance status $\leq 3$, no prior thoracic irradiation, no previous or concurrent illness that would compromise the completion of RT, and follow-up period $\geq 6$ months. Patients who underwent radiosurgery or pre-RT surgical resection were excluded from this study. Patients who did not have available data of pre-RT DMrelated serologic factors (HbA1c and fasting glucose) were also excluded. From January 2011 to December 2017, 767 patients with pathologically confirmed primary lung cancer received RT at Kyung Hee University Medical Center or Kyung Hee University Hospital at Gangdong. Of those patients, 289 who underwent pre-RT surgical resection, 110 who received a total $\mathrm{RT}$ dose $\leq 50 \mathrm{~Gy}, 87$ who had prior thoracic irradiation, 69 who underwent radiosurgery, and 35 who had poor general condition (ECOG performance status $\geq 4$ ) were excluded. Fifty-four patients who did not have available follow-up data were also excluded. Finally, 123 patients met the inclusion criteria and were included in this study. The hospital records, results of imaging studies, and laboratory results of all study participants were retrospectively reviewed. The Institutional Review Boards of our institutions approved this study
(KMC IRB 1819-09) and all research was carried out in compliance with the Helsinki Declaration. Because this was retrospective observational study, the Institutional Review Boards of our institutions waived the need for written informed consent.

The initial diagnosis of lung cancer was pathologically confirmed in all patients based on either endoscopic bronchial or percutaneous needle biopsy. Pretreatment evaluation consisted of complete history and physical examination, basic laboratory studies, pulmonary function test, electrocardiogram, trans-thoracic echocardiogram, chest radiography, chest computed tomography (CT) scan, brain magnetic resonance imaging, and positron emission tomography (PET). The cancer stage was restaged according to the 8th edition of the American Joint Committee on Cancer staging system. We retrospectively reviewed hospital records and identified whether each patient had DM or not. All patients were checked HbA1c and fasting glucose level 1 week before the start of RT.

All patients received CT-planned RT. The gross tumor volume (GTV) encompassed the primary tumor and grossly involved lymph nodes visualized on chest CT and PET. The clinical target volume (CTV) included the GTV plus a 6-8 $\mathrm{mm}$ margin, and the planning target volume (PTV) was created by adding an $8-15 \mathrm{~mm}$ margin to the CTV. The patients, who cooperated well with the instructions of medical staff, underwent four-dimensional CT simulation to track the movement of the targets along the respiratory cycle. In the patients who underwent fourdimensional CT simulation, GTV was created using maximal intensity projection images and the CTV included the GTV plus a 6-8 $\mathrm{mm}$ margin. The PTV was created by adding a 3-5 $\mathrm{mm}$ margin to the CTV. Elective nodal irradiation was not performed in all patients. Prescription dose was determined by a radiation oncologist based on the size of the target lesions, the patient's general condition, and the probability of RT-induced toxicity. A daily dose of 1.8-4 Gy was delivered at five fractions per week, resulting in a total dose of 50-72 Gy. For standard comparison of different RT dose schedules, biologically equivalent doses were calculated using a linear quadratic model with an $\alpha / \beta$ ratio of 10 . The sequence and regimen of chemotherapy were individualized based on patient performance status and compliance.

Patients were evaluated with weekly chest X-ray during RT. Follow-up visits were scheduled 2 weeks after completion of RT and every 1-2 months thereafter. Visits 
were more frequent for those who experienced treatmentrelated toxicities. Complete history and physical examination, basic laboratory studies, and chest radiograph were conducted at each follow-up visit. Chest CT and PET were also performed as needed. Radiation pneumonitis was diagnosed by a treating radiation oncologist on the basis of clinical symptoms and characteristic imaging findings within the RT field, and scored according to the toxicity criteria of the Radiation Therapy Oncology Group. Patients presenting with severe symptoms unresponsive to antitussive agents with suspicious radiologic changes were treated with steroids and scored as grade 3 radiation pneumonitis.

Binary logistic regression analysis was used to identify significant predictive factors for the development of grade $\geq 3$ radiation pneumonitis. Because of the close association among the RT dosimetric factors, we only included V20 and mean lung dose in the statistical analysis. V20 is the volume of lung to receive $>20 \mathrm{~Gy}$ and volume of lung was defined as total lung volume minus PTV. Variables found to have a $P$-value $<0.10$ on univariable analysis were further analyzed by multivariable analysis using binary logistic regression analysis with a backward stepwise method. Because DM, HbAlc, and fasting glucose are closely associated with one another, we included them separately in multivariable analysis. To find the best cutoff values of $\mathrm{HbAlc}$ and fasting glucose level, we conducted receiver operating characteristic analysis. All tests were two-sided and a $P$-value $<0.05$ was considered statistically significant. All analyses were performed using SPSS version 21.0 (IBM Corporation, Armonk, NY, USA).

\section{Results}

Patient and tumor characteristics are summarized in Table 1. All patients were followed for more than 12 months. During the follow-up period, 122 patients experienced radiation pneumonitis. Grade 1 radiation pneumonitis developed in 52 patients (42.3\%), grade 2 in 36 patients (29.2\%), and grade 3 in 34 patients (27.6\%). Only one patient experienced grade 4 radiation pneumonitis. Cumulative incidence of grade $\geq 3$ radiation pneumonitis is depicted in Figure 1. All patients with grade $\leq 3$ radiation pneumonitis were successfully treated with conservative management and some of the patients with grade 3 radiation pneumonitis were treated with steroid agents. However, because the patient who experienced grade 4 radiation pneumonitis did not achieve symptomatic relief, the patient was intubated and placed on a ventilator. There was no radiation pneumonitis-related death during follow-up duration.
Predictive factors for grade $\geq 3$ radiation pneumonitis were analyzed and are summarized in Tables 2 and 3. On univariable analysis, V20 (odds ratio $=1.064,95 \%$ $\mathrm{CI}=1.024-1.106, \quad P=0.001$ ), mean lung dose (odds ratio $=1.121,95 \% \mathrm{CI}=1.038-1.210, P=0.003$ ), DM (odds ratio $=3.067,95 \% \mathrm{CI}=1.327-7.085, P=0.009), \quad \mathrm{HbA1c}$ (odds ratio $=1.744,95 \% \mathrm{CI}=1.277-2.383, P<0.001$ ), and fasting glucose level (odds ratio $=1.014,95 \% \mathrm{CI}=1.005$ 1.022, $P=0.003$ ) were significantly associated with the development of grade $\geq 3$ radiation pneumonitis. On multivariable analysis, V20 (odds ratio $=1.055,95 \% \mathrm{CI}=1.008$ 1.104, $P=0.022$ ), mean lung dose (odds ratio $=1.110,95 \%$ $\mathrm{CI}=1.012-1.218, P=0.027$ ), DM (odds ratio $=2.710,95 \%$ $\mathrm{CI}=1.048-7.004, P=0.040$ ), HbA1c (odds ratio=1.510, $95 \% \mathrm{CI}=1.067-2.137, P=0.020)$, and fasting glucose level (odds ratio $=1.011,95 \% \mathrm{CI}=1.001-1.021, P=0.031$ ) remained significant predictive factors for grade $\geq 3$ radiation pneumonitis. Gender, ECOG performance status, RT technique (three-dimensional vs four-dimensional), and GTV were marginally significant on univariable analysis. However, not all of these remained significant predictive factors on multivariable analysis. The incidence of grade $\geq 3$ radiation pneumonitis was $44.4 \%$ in patients with DM and $20.7 \%$ in patients without DM.

According to receiver operating characteristic analysis, the best cutoff values of HbA1c and fasting glucose level were $\quad 6.15 \% \quad$ (sensitivity $=75.9 \%, \quad$ specificity $=69.6 \%$, $P<0.001$ ) and $121 \mathrm{mg} / \mathrm{dL}$ (sensitivity $=69 \%$, specificity $=57 \%, P=0.003$ ), respectively. The incidence of grade $\geq 3$ radiation pneumonitis was $12.7 \%$ for $\mathrm{HbAlc}$ level $\leq 6.15 \%$ and $41.5 \%$ for $\mathrm{HbA} 1 \mathrm{c}$ level $>6.15 \%$. The incidence of grade $\geq 3$ radiation pneumonitis was $17.2 \%$ for fasting glucose level $\leq 121 \mathrm{mg} / \mathrm{dL}$ and $35.5 \%$ for fasting glucose level $>121 \mathrm{mg} / \mathrm{dL}$.

\section{Discussion}

Hsia et al retrospectively analyzed the clinical data of 118 lung cancer patients and reported that DM itself was not associated with higher radiation pneumonitis risk. ${ }^{20}$ Orton et al also evaluated the correlation between DM and radiation pneumonitis in 66 patients with lung cancer and reported that the rate of radiation pneumonitis in patients with DM was not significantly different from that in patients without DM, although the patients with DM showed higher incidence of radiation pneumonitis. ${ }^{18}$ In People's Republic of China, two retrospective studies evaluated the relationship between DM and the incidence of radiation pneumonitis in patients with lung cancer and 
Table I Patient and tumor characteristics

\begin{tabular}{|c|c|}
\hline Characteristics & $\mathbf{N}(\%)$ \\
\hline \multicolumn{2}{|l|}{ Age (years) } \\
\hline Median (range) & $68(28-87)$ \\
\hline \multicolumn{2}{|l|}{ Gender } \\
\hline Male/female & $99(80.5) / 24(19.5)$ \\
\hline \multicolumn{2}{|l|}{ ECOG performance status } \\
\hline $0 / 1 / 2 / 3$ & $15(12.2) / 63(5 I .2) / 42(34.1) / 3(2.5)$ \\
\hline \multicolumn{2}{|l|}{ AJCC stage } \\
\hline I/II/III & I5 (I2.2)/I7 (I3.8)/9I (74.0) \\
\hline \multicolumn{2}{|l|}{ Site } \\
\hline Right/left & $62(50.4) / 61(49.6)$ \\
\hline \multicolumn{2}{|l|}{ Smoking status } \\
\hline Never/former/current & $25(20.4) / 43(34.9) / 55(44.7)$ \\
\hline \multicolumn{2}{|l|}{ Underlying lung disease } \\
\hline Yes/no & $26(21.1) / 97(78.9)$ \\
\hline \multicolumn{2}{|l|}{ Histology } \\
\hline SqCC/adenoca/SCLC/ & 5 I (4I.5)/28 (22.8)/34 (27.6)/7 \\
\hline NSCLC/NEC & $(5.7) / 3(2.4)$ \\
\hline \multicolumn{2}{|l|}{ Chemotherapy } \\
\hline Yes/no & $78(63.4) / 45(36.6)$ \\
\hline \multicolumn{2}{|l|}{ Chemotherapy } \\
\hline Con/ind/adj/ind+con & $60(76.9) / 13(16.7) / 2(2.6) / 3(3.8)$ \\
\hline \multicolumn{2}{|l|}{ RT technique } \\
\hline 3D-CRT/IMRT & $50(40.7) / 73(59.3)$ \\
\hline \multicolumn{2}{|l|}{ RT technique } \\
\hline 3D simulation/4D simulation & $74(60.2) / 49(39.8)$ \\
\hline \multicolumn{2}{|l|}{ Total dose (BED, Gyı) } \\
\hline Median (range) & $76.2(60-86.4)$ \\
\hline \multicolumn{2}{|l|}{ Daily dose (Gy) } \\
\hline Median (range) & $2(1.8-4)$ \\
\hline \multicolumn{2}{|l|}{ GTV (cc) } \\
\hline Median (range) & I07 (3.4-I I88.2) \\
\hline \multicolumn{2}{|l|}{ V20 (\%) } \\
\hline Median (range) & $23.0(5.0-52.1)$ \\
\hline \multicolumn{2}{|l|}{ Mean lung dose (Gy) } \\
\hline Median (range) & $13.5(5.8-30.2)$ \\
\hline \multicolumn{2}{|l|}{ Diabetes mellitus } \\
\hline Yes/no & $36(29.3) / 87(70.7)$ \\
\hline \multicolumn{2}{|l|}{ HbAlc (\%) } \\
\hline Median (range) & $6.1(4.9-12.2)$ \\
\hline
\end{tabular}

(Continued)
Table I (Continued).

\begin{tabular}{|l|l|}
\hline Characteristics & N (\%) \\
\hline $\begin{array}{l}\text { Fasting glucose (mg/dL) } \\
\text { Median (range) }\end{array}$ & $122.5(73 . \mathrm{I}-294.2)$ \\
\hline
\end{tabular}

Abbreviations: ECOG, Eastern Cooperative Oncology Group; AJCC, American Joint Committee on $\mathrm{Cancer}$; $\mathrm{SqCC}$, squamous cell carcinoma; adenoca, adenocarcinoma; SCLC, small cell lung cancer; NSCLC, non-small cell lung cancer; NEC, neuroendocrine carcinoma; con, concurrent; ind, induction; adj, adjuvant; RT, radiotherapy; 3D-CRT, three-dimensional conformal radiotherapy; IMRT, intensity-modulated radiotherapy; 3D, three-dimensional; 4D, four-dimensional; BED, biologically equivalent dose; GTV, gross tumor volume; $\mathrm{HbAlc}$, hemoglobin Alc.

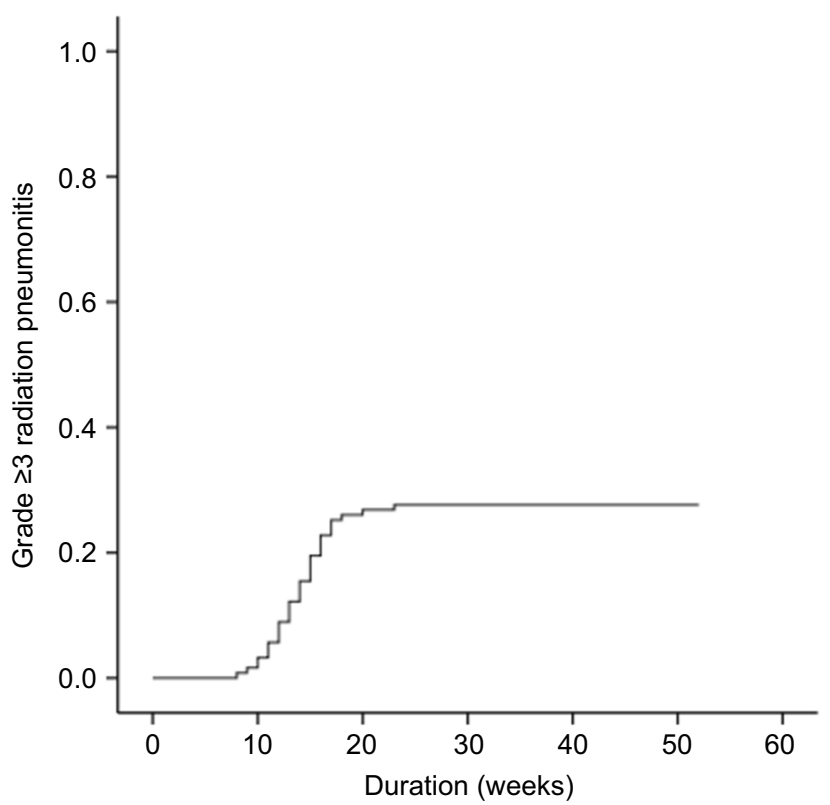

Figure I Cumulative incidence of grade $\geq 3$ radiation pneumonitis among all patients. Grade 3 radiation pneumonitis developed in 34 patients $(27.6 \%)$ and grade 4 developed in I patient.

reported that DM is a significant risk factor for radiation pneumonitis. ${ }^{19,21}$ However, the two studies conducted in People's Republic of China were published in Chinese, and Hsia et al's and Orton et al's studies were published only abstract form, so we were not able to review the full text. In our study of 123 patients, we evaluated the effects of DM and DM-related serologic factors ( $\mathrm{HbAlc}$ and fasting glucose) on the development of radiation pneumonitis in patients with lung cancer. On uni- and multivariable analyses, DM, HbAlc, and fasting glucose level were significantly associated with the development of grade $\geq 3$ radiation pneumonitis. This is one of the first studies to report the impacts of DM and DM-related serologic factors on the development of radiation pneumonitis. 
Table 2 Univariable analysis to identify predictive factors for grade $\geq 3$ radiation pneumonitis

\begin{tabular}{|c|c|c|c|}
\hline Variable & Odds ratio & $95 \%$ confidence interval & $P$-value \\
\hline Age (years) & 1.001 & $0.961-1.042$ & 0.957 \\
\hline \multicolumn{4}{|l|}{ Gender } \\
\hline Male & 1 & & \\
\hline Female & 3.191 & $0.885-11.502$ & 0.076 \\
\hline \multicolumn{4}{|l|}{ ECOG performance status } \\
\hline $0-1$ & 1 & & \\
\hline $2-3$ & 2.050 & $0.906-4.638$ & 0.085 \\
\hline \multicolumn{4}{|l|}{ AJCC stage } \\
\hline $1-2$ & $\mathrm{I}$ & & \\
\hline 3 & 1.926 & $0.713-5.199$ & 0.196 \\
\hline \multicolumn{4}{|l|}{ Smoking status } \\
\hline Never & 1 & & \\
\hline Former or current & 1.267 & $0.458-3.503$ & 0.649 \\
\hline \multicolumn{4}{|l|}{ Lung disease } \\
\hline No & 1 & & \\
\hline Yes & 1.525 & $0.603-3.854$ & 0.373 \\
\hline \multicolumn{4}{|l|}{ Chemotherapy } \\
\hline No & 1 & & \\
\hline Yes & 1.293 & $0.560-2.982$ & 0.547 \\
\hline V20 (\%) & 1.064 & $1.024-1.106$ & 0.001 \\
\hline Mean lung dose (Gy) & 1.121 & $1.038-1.210$ & 0.003 \\
\hline \multicolumn{4}{|l|}{ RT technique } \\
\hline 3D-CRT & 1 & & \\
\hline IMRT & 0.821 & $0.369-1.826$ & 0.629 \\
\hline \multicolumn{4}{|l|}{ RT technique } \\
\hline 3D simulation & 1 & & \\
\hline 4D simulation & 2.105 & $0.944-4.695$ & 0.069 \\
\hline Total RT dose (BED, Gy, & 0.976 & $0.924-1.030$ & 0.371 \\
\hline Daily RT dose (Gy) & 1.507 & $0.454-5.004$ & 0.503 \\
\hline GTV (cc) & 1.001 & $1.000-1.003$ & 0.079 \\
\hline \multicolumn{4}{|l|}{ Diabetes mellitus } \\
\hline No & 1 & & \\
\hline Yes & 3.067 & $1.327-7.085$ & 0.009 \\
\hline HbAlc (\%) & 1.744 & $1.277-2.383$ & $<0.001$ \\
\hline Fasting glucose (mg/dL) & 1.014 & $1.005-1.022$ & 0.003 \\
\hline
\end{tabular}

Abbreviations: ECOG, Eastern Cooperative Oncology Group; AJCC, American Joint Committee on Cancer; RT, radiotherapy; 3D-CRT, three-dimensional conformal radiotherapy; IMRT, intensity-modulated radiotherapy; 3D, three-dimensional; 4D, four-dimensional; BED, biologically equivalent dose; GTV, gross tumor volume; HbAIc, hemoglobin Alc.

The pathophysiologic process of radiation pneumonitis involves inflammation, epithelial degeneration, endothelial sloughing, disruption of microvasculature, induction of free radicals, and the accompanying oxidative stress. ${ }^{22}$ It is well known that chronic DM causes inflammation, oxidative stress, endothelial dysfunction, and microvascular occlusive changes. ${ }^{23,24}$ Chronic DM also causes alterations in blood viscosity, which contributes to tissue ischemia. ${ }^{25}$ All changes caused by DM are involved in the pathophysiologic process of radiation pneumonitis, and those changes aggravate the deleterious effects of RT and disturb the repair of damaged pulmonary tissues. It is possible that 
Table 3 Multivariable analysis to identify predictive factors for grade $\geq 3$ radiation pneumonitis

\begin{tabular}{|c|c|c|c|}
\hline Variable & Odds ratio & $95 \%$ confidence interval & $P$-value \\
\hline \multicolumn{4}{|l|}{ Gender } \\
\hline Male & 1 & & \\
\hline Female & 2.267 & $0.562-9.144$ & 0.250 \\
\hline \multicolumn{4}{|l|}{ ECOG performance status } \\
\hline $0-1$ & 1 & & \\
\hline $2-3$ & 1.575 & $0.604-4.104$ & 0.353 \\
\hline V20 (\%) & 1.055 & $1.008-1.104$ & 0.022 \\
\hline Mean lung dose (Gy) & 1.110 & $1.012-1.218$ & 0.027 \\
\hline \multicolumn{4}{|l|}{ RT technique } \\
\hline 3D simulation & 1 & & \\
\hline 4D simulation & 1.663 & $0.592-4.672$ & 0.335 \\
\hline GTV (cc) & 1.001 & $0.998-1.003$ & 0.647 \\
\hline \multicolumn{4}{|l|}{ Diabetes mellitus } \\
\hline No & 1 & & \\
\hline Yes & 2.710 & $1.048-7.004$ & 0.040 \\
\hline HbAlc (\%) & 1.510 & $1.067-2.137$ & 0.020 \\
\hline Fasting glucose $(\mathrm{mg} / \mathrm{dL})$ & 1.011 & $1.001-1.021$ & 0.031 \\
\hline
\end{tabular}

Abbreviations: ECOG, Eastern Cooperative Oncology Group; RT, radiotherapy; 3D, three-dimensional; 4D, four-dimensional; GTV, gross tumor volume; HbAlc, hemoglobin Alc.

these are the reasons why patients with DM in our study experienced higher incidence of grade $\geq 3$ radiation pneumonitis than patients without DM (44.4\% vs $20.7 \%$, $P=0.009$ ). For the same reasons, patients who have higher HbA1c $(41.5 \%$ vs $12.7, P<0.001)$ or fasting glucose (35.5\% vs $17.2 \%, P=0.003)$ experienced higher grade $\geq 3$ radiation pneumonitis in this study.

Although four-dimensional CT moving images may increase the certainty of the targets and lead to a reduction in unnecessary PTV margins, the patients who received four-dimensional RT showed a higher incidence of grade $\geq 3$ radiation pneumonitis compared with patients who underwent three-dimensional RT in this study $(36.7 \%$ vs $21.6 \%$, odds ratio $=2.105,95 \% \mathrm{CI}=0.944-4.695, P=0.069)$. We added PTV margins of $8-15 \mathrm{~mm}$ in patients who underwent three-dimensional RT, while we added 3-5 $\mathrm{mm}$ margins in patients who underwent four-dimensional RT. However, to include all images of 10 respiratory phases, we created GTV using maximal intensity projection images. Because the GTVs created by maximal intensity projection images were bigger than the GTVs created by three-dimensional CT images, the PTVs of four-dimensional RT were bigger than those of three-dimensional RT despite of lesser margins (median $215 \mathrm{cc}$ vs $183 \mathrm{cc}$, $P=0.049$ ). These reasons may be why the patients who received four-dimensional RT showed a higher incidence of grade $\geq 3$ radiation pneumonitis compared with patients who received three-dimensional RT in this study.

There are several studies reporting correlations between RT dosimetric factors and development of radiation pneumonitis. However, all dosimetric parameters are found to be highly correlated with one another and differences in predictive value among different dosimetric parameters tend to be small. ${ }^{4,10,26}$ Because most studies reported that V20 and mean lung dose were the most important predictive factors for radiation pneumonitis, we included only V20 and mean lung dose in the statistical analysis to minimize potential confounding factors.

$\mathrm{DM}$ is one of the most common endocrine diseases worldwide, with a prevalence of $11 \%$ in Koreans over the age of 30 years. ${ }^{27}$ In our study, $29.3 \%$ of the overall patient population was diagnosed with DM. Other studies reported DM in $14-33.3 \%$ of their patient groups. ${ }^{18-21}$ Because several studies showed a higher prevalence of DM in lung cancer patients compared with the general population, greater caution is warranted in implementation of RT and posttreatment monitoring for lung cancer patients. In addition, it is critical that the interactions between DM and potential DM-associated RT toxicities in this patient group should be further characterized. Our 
study provides valuable information regarding the interactions between DM and RT toxicities in patients with lung cancer. Large-scale randomized prospective studies should be conducted to confirm our results.

Recently, personalized medicine has become a hot topic due to the lower cost of genetic testing and abundant research findings. ${ }^{28}$ Several studies have conducted to find lung biomarkers predicting the development of radiation pneumonitis, and IL-6, TGF- $\beta$, and surfactant apoprotein are known to be novel biomarkers predicting radiation pneumonitis. ${ }^{29-31}$ It may be useful to combine well-known dosimetric parameters such as V20 and mean lung dose with various lung biomarkers to define a subgroup of patients with higher risk for radiation pneumonitis. In addition, DM, HbAlc, and fasting glucose level can be also combined with dosimetric parameters and lung biomarkers to further allow personalized thoracic RT. We hope further studies are conducted to confirm the efficacy of personalized thoracic RT combining dosimetric parameters, novel lung biomarkers, and DMrelated factors in the near future.

There were several limitations in this study. First, this study was retrospective and may therefore have inherent biases. For example, diagnosis of DM was decided retrospectively by reviewing the patients' clinical data. Therefore, we were unable to control for the possibility that patients can develop DM after treatment, which could affect the development of late-onset radiation pneumonitis. In addition, we did not analyze some potential predictive factors for radiation pneumonitis, such as DM medication history. These biases may make it difficult to interpret the results obtained. Second, the sample size was relatively small. Third, the patient and tumor characteristics were heterogeneous. Despite these limitations, we believe our study addresses some unresolved issues regarding the relationship between DM and radiation pneumonitis.

\section{Conclusion}

$\mathrm{DM}, \mathrm{HbA} 1 \mathrm{c}$, and fasting glucose level are significant predictive factors for the development of grade $\geq 3$ radiation pneumonitis in patients with lung cancer. Patients with DM, patients who have HbAlc $>6.15 \%$, and patients who have fasting glucose $>121 \mathrm{mg} / \mathrm{dL}$ should be treated with greater caution.

\section{Acknowledgment}

This research was supported by a grant of the Korea Health Technology R\&D Project through the Korea Health Industry Development Institute (KHIDI) funded by the Ministry of Health \& Welfare, Republic of Korea (HI18C1944), supported by the Kyung Hee University Research Fund in 2018 (KHU-20181675), 2016 (KHU20161387), and 2015 (KHU-20152149).

\section{Disclosure}

Prof. Dr Moonkyoo Kong reports grants from the Ministry of Health \& Welfare, Republic of Korea, as well as grants from Kyung Hee University Research Fund, during the conduct of the study. The authors report no other conflicts of interest in this work.

\section{References}

1. Chang JY, Senan S, Paul MA, et al. Stereotactic ablative radiotherapy versus lobectomy for operable stage I non-small-cell lung cancer: a pooled analysis of two randomised trials. Lancet Oncol. 2015;16 (6):630-637. doi:10.1016/S1470-2045(15)70168-3

2. Rodrigues G, Lock M, D’Souza D, Yu E, Van Dyk J. Prediction of radiation pneumonitis by dose - volume histogram parameters in lung cancer - a systematic review. Radiother Oncol. 2004;71(2):127-138. doi:10.1016/j.radonc.2004.02.015

3. Kim Y, Hong SE, Kong M, Choi J. Predictive factors for radiation pneumonitis in lung cancer treated with helical tomotherapy. Cancer Res Treat. 2013;45(4):295-302. doi:10.4143/crt.2013.45.4.295

4. Palma DA, Senan S, Tsujino K, et al. Predicting radiation pneumonitis after chemoradiation therapy for lung cancer: an international individual patient data meta-analysis. Int J Radiat Oncol Biol Phys. 2013;85(2):444-450. doi:10.1016/j.ijrobp.2012.04.043

5. Kim K, Lee J, Cho Y, et al. Predictive factors of symptomatic radiation pneumonitis in primary and metastatic lung tumors treated with stereotactic ablative body radiotherapy. Radiat Oncol J. 2017;35 (2):163-171. doi:10.3857/roj.2017.00066

6. Shi A, Zhu G, Wu H, Yu R, Li F, Xu B. Analysis of clinical and dosimetric factors associated with severe acute radiation pneumonitis in patients with locally advanced non-small cell lung cancer treated with concurrent chemotherapy and intensity-modulated radiotherapy. Radiat Oncol. 2010;5:35. doi:10.1186/1748-717X-5-35

7. Boonyawan K, Gomez DR, Komaki R, et al. Clinical and dosimetric factors predicting grade $>/=2$ radiation pneumonitis after postoperative radiotherapy for patients with non-small cell lung carcinoma. Int J Radiat Oncol Biol Phys. 2018;101(4):919-926. doi:10.1016/j. ijrobp.2018.04.012

8. Onishi H, Kuriyama K, Yamaguchi M, et al. Concurrent two-dimensional radiotherapy and weekly docetaxel in the treatment of stage III non-small cell lung cancer: a good local response but no good survival due to radiation pneumonitis. Lung Cancer. 2003;40(1):7984.

9. Parashar B, Edwards A, Mehta R, et al. Chemotherapy significantly increases the risk of radiation pneumonitis in radiation therapy of advanced lung cancer. Am J Clin Oncol. 2011;34(2):160-164. doi:10.1097/COC.0b013e3181d6b40f

10. Zhang XJ, Sun JG, Sun J, et al. Prediction of radiation pneumonitis in lung cancer patients: a systematic review. J Cancer Res Clin Oncol. 2012;138(12):2103-2116. doi:10.1007/s00432-012-1284-1

11. Zaorsky NG, Shaikh T, Ruth K, et al. Prostate cancer patients with unmanaged diabetes or receiving insulin experience inferior outcomes and toxicities after treatment with radiation therapy. Clin Genitourin Cancer. 2017; 15(2):326-335, e323. doi:10.1016/j.clgc.2016.08.020

12. Kalakota K, Liauw SL. Toxicity after external beam radiotherapy for prostate cancer: an analysis of late morbidity in men with diabetes mellitus. Urology. 2013;81(6):1196-1201. doi:10.1016/j.urology.2013.01.047 
13. Herold DM, Hanlon AL, Hanks GE. Diabetes mellitus: a predictor for late radiation morbidity. Int J Radiat Oncol Biol Phys. 1999;43 (3):475-479. doi:10.1016/s0360-3016(98)00460-x

14. Akimoto T, Muramatsu H, Takahashi M, et al. Rectal bleeding after hypofractionated radiotherapy for prostate cancer: correlation between clinical and dosimetric parameters and the incidence of grade 2 or worse rectal bleeding. Int J Radiat Oncol Biol Phys. 2004;60(4):1033-1039. doi:10.1016/j.ijrobp.2004.07.695

15. Alashkham A, Paterson C, Hubbard S, Nabi G. What is the impact of diabetes mellitus on radiation induced acute proctitis after radical radiotherapy for adenocarcinoma prostate? A prospective longitudinal study. Clin Transl Radiat Oncol. 2019;14:59-63. doi:10.1016/j.ctro.2017.02.003

16. Peairs KS, Barone BB, Snyder CF, et al. Diabetes mellitus and breast cancer outcomes: a systematic review and meta-analysis. J Clin Oncol. 2011;29(1):40-46. doi:10.1200/JCO.2009.27.3011

17. Stein KB, Snyder CF, Barone BB, et al. Colorectal cancer outcomes, recurrence, and complications in persons with and without diabetes mellitus: a systematic review and meta-analysis. Dig Dis Sci. 2010;55 (7):1839-1851. doi:10.1007/s10620-009-0944-8

18. Orton MD, Mukhopadhyay ND, Weiss E. Evaluation of diabetes as a risk factor for the development of clinically symptomatic pneumonitis following Stereotactic Body Radiation Therapy (SBRT). Int J Radiat Oncol Biol Phys. 2013;87(2):S514. doi:10.1016/j.ijrobp.2013.06.1359

19. Zhou H, Cao K, Cao P, Jiang W. [Impact of diabetes mellitus on clinicopathological factors and relation with radiation pneumonitis in 332 patients with lung cancer]. Zhong Nan Da Xue Xue Bao Yi Xue Ban. 2013;38(2):138-141. doi:10.3969/j.issn.1672-7347.2013.02.005

20. Hsia WJ, Jan N, Mukhopadhyay ND, Weiss E. Effect of diabetes mellitus and selected medications on the development of radiation pneumonitis in patients with locally advanced non-small cell lung cancer. Int J Radiat Oncol Biol Phys. 2015;93(3):E403. doi:10.1016/ j.ijrobp.2015.07.1576

21. Song H, Yu JM. [Effect of diabetes mellitus on the development of radiation pneumonitis in patients with non-small cell lung cancer]. Zhonghua Zhong Liu Za Zhi. 2009;31(1):45-47.
22. Trott KR, Herrmann T, Kasper M. Target cells in radiation pneumopathy. Int $J$ Radiat Oncol Biol Phys. 2004;58(2):463-469. doi:10.1016/j.ijrobp.2003.09.045

23. Domingueti CP, Dusse LM, Carvalho M, de Sousa LP, Gomes KB, Fernandes AP. Diabetes mellitus: the linkage between oxidative stress, inflammation, hypercoagulability and vascular complications. J Diabetes Complications. 2016;30(4):738-745. doi:10.10 16/j.jdiacomp.2015.12.018

24. Meyer JS. Diabetes and wound healing. Crit Care Nurs Clin North Am. 1996;8(2):195-201.

25. Morain WD, Colen LB. Wound healing in diabetes mellitus. Clin Plast Surg. 1990;17(3):493-501.

26. Jain V, Berman AT. Radiation pneumonitis: old problem, new tricks. Cancers (Basel). 2018;10:7. doi:10.3390/cancers 10110400

27. Ha KH, Kim DJ. Current status of managing diabetes mellitus in Korea. Korean J Intern Med. 2016;31(5):845-850. doi:10.3904/ kjim.2016.253

28. Palmer JD, Zaorsky NG, Witek M, Lu B. Molecular markers to predict clinical outcome and radiation induced toxicity in lung cancer. J Thorac Dis. 2014;6(4):387-398. doi:10.3978/j.issn.2072-1439. 2013.12.04

29. Hartsell WF, Scott CB, Dundas GS, et al. Can serum markers be used to predict acute and late toxicity in patients with lung cancer? Analysis of RTOG 91-03. Am J Clin Oncol. 2007;30(4):368-376. doi:10.1097/01.coc.0000260950.44761.74

30. Zhao L, Wang L, Ji W, et al. Elevation of plasma TGF-beta1 during radiation therapy predicts radiation-induced lung toxicity in patients with non-small-cell lung cancer: a combined analysis from Beijing and Michigan. Int J Radiat Oncol Biol Phys. 2009;74(5):1385-1390. doi:10.1016/j.ijrobp.2008.10.065

31. Yuan X, Liao Z, Liu Z, et al. Single nucleotide polymorphism at rs1982073: T869Cof the TGFbeta 1 gene is associated with the risk of radiation pneumonitis in patients with non-small-cell lung cancer treated with definitive radiotherapy. J Clin Oncol. 2009;27(20):33703378. doi:10.1200/JCO.2008.20.6763

\section{Publish your work in this journal}

Cancer Management and Research is an international, peer-reviewed open access journal focusing on cancer research and the optimal use of preventative and integrated treatment interventions to achieve improved outcomes, enhanced survival and quality of life for the cancer patient.
The manuscript management system is completely online and includes a very quick and fair peer-review system, which is all easy to use. Visit http://www.dovepress.com/testimonials.php to read real quotes from published authors. 